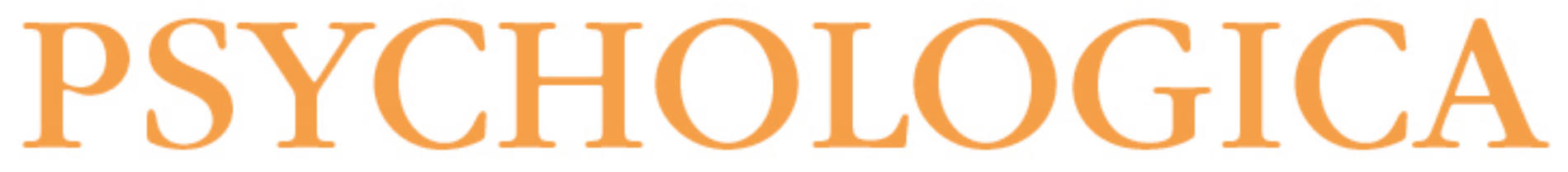

Estudo preliminar do teste Test for Creative Thinking: Drawing Production (TCT-DP)

Autor(es): $\quad$ Almeida, Leonor; Nogueira, Sara Ibérico

Publicado por: Imprensa da Universidade de Coimbra

URL

persistente: URI:http://hdl.handle.net/10316.2/3446

DOI: $\quad$ DOI:http://dx.doi.org/10.14195/1647-8606_52-1_9

Accessed : $\quad$ 26-Apr-2023 13:52:04

A navegação consulta e descarregamento dos títulos inseridos nas Bibliotecas Digitais UC Digitalis, UC Pombalina e UC Impactum, pressupõem a aceitação plena e sem reservas dos Termos e Condições de Uso destas Bibliotecas Digitais, disponíveis em https://digitalis.uc.pt/pt-pt/termos.

Conforme exposto nos referidos Termos e Condições de Uso, o descarregamento de títulos de acesso restrito requer uma licença válida de autorização devendo o utilizador aceder ao(s) documento(s) a partir de um endereço de IP da instituição detentora da supramencionada licença.

Ao utilizador é apenas permitido o descarregamento para uso pessoal, pelo que o emprego do(s) título(s) descarregado(s) para outro fim, designadamente comercial, carece de autorização do respetivo autor ou editor da obra.

Na medida em que todas as obras da UC Digitalis se encontram protegidas pelo Código do Direito de Autor e Direitos Conexos e demais legislação aplicável, toda a cópia, parcial ou total, deste documento, nos casos em que é legalmente admitida, deverá conter ou fazer-se acompanhar por este aviso.

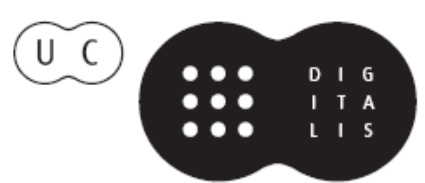




\section{NÚMERO 52}

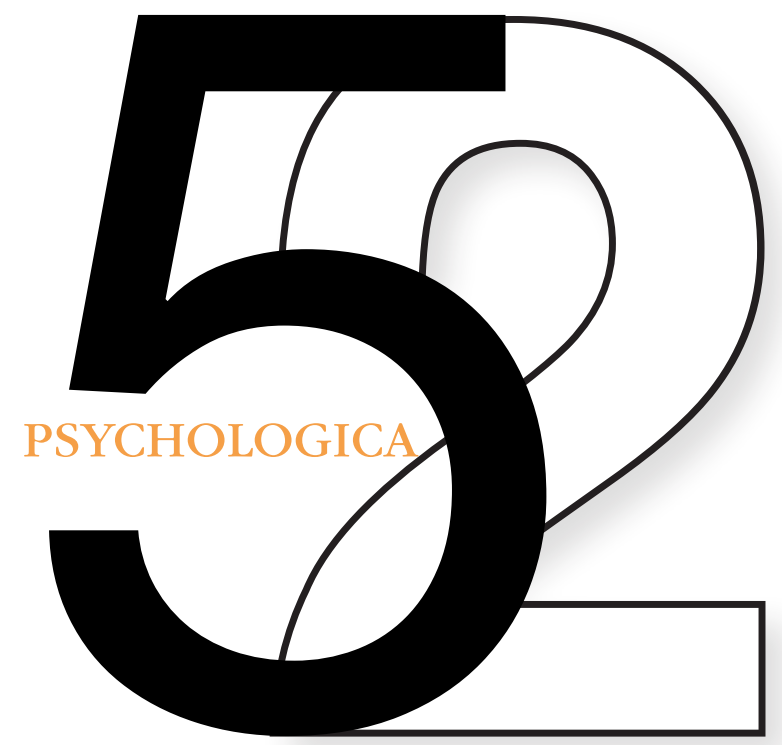

VOLUME I

IMPRENSA DA UNIVERSIDADE DE COIMBRA

FACULDADE DE PSICOLOGIA E DE CIÊNCIAS DA EDUCAÇÃO DA UNIVERSIDADE DE COIMBRA 


\title{
Estudo preliminar do teste Test for Creative Thinking-Drawing Production (TCT-DP)
}

\begin{abstract}
Leonor Almeida', Sara Ibérico Nogueira²
Pretende-se efectuar um estudo Preliminar do teste TCT-DP- Test of Creative Thinking and Drawing Production de Urban e Jellen (1986), que visa uma abordagem holística do denominado pensamento divergente. $O$ teste (Formas A e B) baseia-se em alguns fragmentos de figuras que os sujeitos deverão completar de forma livre. A amostra em que nos baseámos, recolhida em Empresas Consultoras em Recursos Humanos da região de Lisboa, é constituída por 169 trabalhadores Portugueses, com idades superiores a 18 anos e habilitações literárias e profissionais diversas. Para além dos aspectos de adaptação do instrumento à população Portuguesa, foram realizados estudos sobre as qualidades psicométricas do teste na amostra escolhida. Este estudo apontou pistas de investigação relevantes para estudos futuros, exigindo, no entanto, o alargamento da amostra bem como a sua diversificação.
\end{abstract}

PALAVRAS-CHAVE: Test for Creative Thinking-Drawing Production (TCT-DP), Criatividade, Pensamento divergente, Estudo Preliminar.

O alerta lançado por Guilford, em 1950, à APA (American Psychiatric Association), sobre a incompreensível insuficiência de estudos na área da criatividade foi definitivamente tornado mais evidente quando todos os americanos assistiram ao lançamento para o espaço do primeiro satélite russo, o Sputnick, não podendo deixar de se questionar seriamente sobre as razões que tinham levado a que tanta acumulação de saberes não tivesse tido os resultados esperados em termos de produtos criativos tão essenciais à chamada Guerra Fria.

Guilford (1950) obrigou a que se lançasse um novo olhar sobre o conceito de criatividade demasiado apegado, até essa altura, aos processos de insight que súbita e repentinamente pareciam bafejar apenas alguns privilegiados, fossem eles um Newton, um DaVinci ou um Dali. Nesse sentido, pela sua própria natu-

\footnotetext{
1 Departamento de Psicologia, Universidade Lusófona de Humanidades e Tecnologias - Ialmeida@ ulusofona.pt

2 Departamento de Psicologia, Universidade Lusófona de Humanidades e Tecnologias - saraiberico@ hotmail.com
} 
reza eminentemente rara, a criatividade desafiaria qualquer definição (Torrance, 1988). A esta, acresceria outra dificuldade: a de inclusivamente a nível dos sujeitos considerados mais eminentemente criativos, não podermos esperar sempre a mesma constância em termos de produtividade, nem tão pouco o mesmo nível de genialidade (Simonton, 1988).

Guilford, contudo, foi-nos habituando à ideia de que as pessoas comuns poderiam ser igualmente criativas. Na acepção de Stein (1987) e Treffinger (1987), a distinção entre a Pequena e a Grande Criatividade permitiria aceitar a possibilidade de todos nós podermos evidenciar e desenvolver a dita Pequena Criatividade, ou os processos de pensamento divergente. Digamos que esta Pequena Criatividade estaria ao alcance de todos nós e que poderia ser considerada uma peça indispensável à emergência da Grande Criatividade. Aliás, os estudos longitudinais de Torrance (1988), efectuados com estudantes universitários e com sujeitos do $1^{\circ}$ e $2^{\circ}$ anos de escolaridade, em diferentes períodos da sua vida, bem como a revisão de estudos sobre o índice de validade preditiva entre os resultados nos testes de pensamento divergente e o desempenho criativo nos mais diversos níveis de ensino (Barron \& Harrington, 1981), são a esse propósito bem elucidativos.

Se a Grande Criatividade parece seguir a forma altamente assimétrica de um J invertido, a Pequena Criatividade já segue a mais conhecida curva normal de distribuição. Isto quer dizer que a distribuição dos produtos altamente criativos, sejam eles científicos, tecnológicos ou artísticos, parece fazer-se de forma extremamente elitista, porque produzidos, na sua maioria, por um pequeno número de sujeitos (Simonton, 1988; Walberg, 1988). Contudo, as qualidades de pensamento divergente poderiam ser detectadas na grande maioria da população.

Não queremos, no entanto, fazer uma leitura demasiado ingénua e reducionista destas constatações, pois ao fenómeno da emergência dos produtos altamente revolucionários, não é alheio o contexto sócio-cultural em que se está inserido. Segundo Csikszentmihalyi (1988a), a grande questão "Onde está a criatividade?" deveria substituir a já velha e deformada questão "O que é a criatividade". Deformada, pois tentarmos definir a criatividade como uma característica inerente a um sujeito, sem atendermos à valorização que o contexto mais vasto possa fazer dos produtos criativos, seria no mínimo parcial. A criatividade não se explica tendo apenas como referência o Indivíduo e o seu trabalho. O Domínio de especialistas será vital para poder ajudar a diferenciar aquilo que é inovação daquilo que é apenas bizarro ou improvável e o Campo de professores, historiadores, galeristas e críticos, responsáveis pela transmissão da informação simbólica à geração que a procede, constituem um crivo que permite diferenciar o que deve e o que não deve ser preservado, acabando por redefinir o próprio Domínio em causa. Digamos que o contexto histórico-cultural em que emergem os produtos criativos constitui 
um ponto de referência sem o qual o fenómeno da criatividade não tem lugar. No mesmo sentido, para Simonton (1988), o zeigeist pode promover ou, pelo contrário, impedir a produção criativa. As denominadas "épocas de ouro" do Renascimento ou da Antiguidade Clássica, bem como a rejeição de um Rembrant no seu tempo, elucidam-nos sobre a leitura que um certo zeigeist pode fazer sobre a relevância ou insignificância dos produtos criativos dos mais variados tipos.

Compreendemos, desta forma, que vão ganhando relevo as denominadas abordagens da confluência, emergentes na década de 80, através de Amabile (1983), Sternberg e Lubart (1991), Gardner (1988) e Csikszentmihalyi (1988b) que tentam elaborar modelos que integrem os aspectos cognitivos (capacidades e conhecimentos relevantes, estilos cognitivos e pessoais), é certo, mas igualmente os afectivos e os contextuais, onde as características pessoais, motivacionais, bem como as relativas ao ambiente apoiante e recompensador, assumem igual relevo. A metáfora da bolsa de valores, inerente à teoria do investimento na criatividade de Sternberg e Lubart (1996), aponta a coragem do sujeito criativo ao "comprar em baixa", ou seja, defendendo conceitos pouco usuais ou fora de moda, acreditando, no entanto, na sua valorização, vendendo mais tarde "em alta". Vale, por isso, a pena, como referem os autores, investir na criatividade. Se as capacidades de aprendizagem e de memória da mente humana são rapidamente superadas pelas novas tecnologias, a tónica deve ser colocada na criatividade, isto é, na produção de ideias inovadoras nos vários domínios do conhecimento científico, tecnológico, artístico ou humanístico.

Einstein, considerando insultuosa a crença de que a criatividade seria um produto supérfulo e luxuoso, foi-nos habituando à ideia de que a solução para os grandes problemas da humanidade, tais como a fome, a pobreza ou o aumento demográfico, passaria inevitavelmente pelo desenvolvimento, em todos nós, das formas criativas de pensamento, das ideias díspares, alternativas e inovadoras, pouco coladas ao pensamento convencional.

De facto, as transformações científicas e tecnológicas a que assistimos nos últimos 100 anos, reclamam novas perspectivas e diferentes pontos de referência sobre o conceito de criatividade e o modo de a fomentar, estando certos de que apenas vingarão as soluções mais inovadoras.

Paradoxal é o facto das nossas práticas educativas, na sua maioria, desencorajarem a criatividade, ou pior do que isso, puni-la e, paulatinamente, refreá-la e dotá-la de uma auréola malévola, dificultando o bom relacionamento entre as pessoas ou, em primeira instância, entre pais e filhos ou alunos e professores (Sternberg \& Lubart, 1996). Por uma questão de sobrevivência pessoal, rapidamente se aprende a calar os comentários possivelmente disparatados, a concordar, a encontrar para o problema uma única solução securizante, não permitindo que se aprenda a 
lidar com a insegurança e imprevisibilidade inerente a um processo de procura mais aprofundado.

As constantes mudanças e desafios a que hoje em dia somos submetidos no contexto de trabalho, obrigam a que todos estejamos altamente preparados, não 196 apenas em termos de competências técnicas em stricto sensu, mas em termos de formas alternativas e criativas de pensamento, que permita diferenciar-nos e, porque não, sobrevivermos, nesse meio altamente competitivo.

Esta consciencialização, por parte das organizações tem levado à organização de cursos de formação, "Criatividade e Inovação", "Competir na economia criativa”, "Criatividade nas cidades", onde claramente a vertente criatividade aparece em primeiro plano.

Perante todo este contexto teórico, torna-se compreensível o esforço no sentido de criar instrumentos de avaliação da criatividade dos sujeitos, para melhor os poder caracterizar e adequar às funções para os quais possam estar eventualmente destinados. Servem igualmente esses instrumentos para aferir possíveis melhoramentos nos níveis de criatividade dos sujeitos submetidos a algum programa de desenvolvimento das formas criativas de pensamento. O teste proposto por Guilford, embora não pioneiro, mas porque inserido num tipo de avaliação de cariz mais psicométrico, e por isso culturalmente mais significativo, serviu de matriz a muitas outras formas de avaliação.

O TTCT (Torrance's Test of Creative Thinking) de Torrance (1976) é, sem dúvida, um dos testes mais divulgados, adaptados e aferidos em todo o mundo. A sua forma sistemática de cotação, a precisão teste-reteste e a fidelidade inter-cotadores, tornam-no num instrumento poderoso. Este teste, constituído por três testes figurativos e sete testes verbais, obriga a um longo tempo de aplicação e de cotação das respostas, tornando-se não raras vezes de difícil exequibilidade. Por isso, a procura de instrumentos com uma maior abrangência cultural, mais simples e económicos nas aplicações, continua a ser uma realidade.

Jellen e Urban (1986) desenvolveram um modelo baseado em seis componentes que interactuam e se influenciam mutuamente, intervindo na globalidade do processo criativo.Os componentes a que o autor faz alusão são os seguintes: "Pensamento Divergente e Acção", "Conhecimento Geral e Pensamento de Base", "Conhecimento de Base Específico e Aptidões em Áreas Específicas", "Concentração e Empenho na Tarefa", "Motivação e Motivos e "Abertura e Tolerância à Ambiguidade."

De acordo com este modelo componencial, que obriga a uma leitura mais compreensiva do fenómeno da criatividade, estaríamos assim, em melhores condições 
para desenvolver e aceder à criatividade nos indivíduos. Pressupõe-se, ainda, que para além das variáveis individuais, como a motivação e traços cognitivos, deveremos ter em conta a influência dos recursos materiais e dos obstáculos sociais. Assim, à avaliação das características componenciais e de procedimento, deveríamos acrescentar uma análise do produto criativo final.

De acordo com este modelo, Jellen e Urban (1986) criam um instrumento, o TCTDP (Test for Creative Thinking - Drawing Production), caracterizado por permitir aceder ao potencial criativo global do indivíduo. Este instrumento diverge do de Torrance, não só pela possibilidade de aplicação a sujeitos extremamente variáveis em termos etários, como pela sua simplicidade e economia na aplicação, correcção e interpretação, para além de permitir identificar os sujeitos mais extremos (pela positiva e pela negativa), em termos de níveis de criatividade.

O modelo de Urban tem originado um grande número de investigações, algumas das quais tentam evidenciar as características de validade do instrumento, permitindo discriminar sujeitos mais e menos criativos, independentemente dos seus níveis de desenvolvimento intelectual (Wolanska \& Neçka (1994), cit. por Urban, 2004). Nesse mesmo sentido, Wolanska e Neçka, no seu estudo polaco do TCTDP, analisaram as correlações entre o teste de inteligência Matrizes Progressivas de Raven e o TCT-DP numa amostra de 600 sujeitos com idades compreendidas entre os 7 e os 18 anos. O resultado foi o esperado, não existindo uma correlação significativa entre as pontuações das Matrizes Progressivas de Raven e as pontuações do TCT-DP, apoiando assim a validade discriminante do teste.

Cramond e Urban (1995, cit. por Urban, 2004) realizaram um estudo comparativo entre os resultados obtidos no Torrance Test of Creative Thinking e no TCT-DP, em duas amostras de estudantes universitários Americanos e Alemães. Os alunos que tinham optado por áreas consideradas mais criativas foram aqueles que por excelência mais se distinguiram a nível dos resultados obtidos no TCT-DP, não sendo essas diferenças tão marcantes ao considerar o TTCT, sugerindo-se assim o elevado nível de validade daquele mesmo instrumento.

Gefferth (cit. por Urban, 1994) aplicou na Hungria, o TCT-DP a uma amostra de 1000 estudantes do quarto ano. O TCT-DP foi entregue com um questionário especial composto por perguntas acerca das experiências pessoais do sujeito e alguns dados biográficos. Foram compostos dois grupos de estudantes, um com pelo menos 75 pontos no conjunto da forma A e B e o outro com pontuações inferiores a 20. O objectivo foi comparar os extremos do grupo e verificar se existiam diferenças entre os mesmos e as suas relações com os dados biográficos. Os resultados indicaram que os estudantes com um alto potencial criativo, de acordo com o TCT-DP, nomeavam mais passatempos, pareciam mais interessados 
e mais orientados, possuíam mais interesses profissionais e piores resultados a matemática que o seu grupo de comparação (com baixo potencial criativo), o que indicava, mais uma vez, a baixa correlação deste instrumento com o desempenho académico e com as questões tradicionais de Q.I..

198 Rudowicz e Hui (2004) realizaram um estudo em 2368 estudantes chineses com idades compreendidas entre os 12 e 16 anos e recolhem evidência empírica sobre a fidelidade e a validade de constructo, de conteúdo e discriminante do TCT-DP. Outras investigações (Gefferth, cit. por Urban, 2004) apontam correlações elevadas entre os níveis de criatividade e os níveis de motivação e de capacidade de decisão no processo de orientação escolar e profissional. Outras, ainda, evidenciam correlações elevadas entre os níveis de criatividade obtidos pelo TCT-DP e os prémios obtidos por uma série de estudantes de engenharia (Jellen \& Bugingo, 1989).

Considerando a inexistência em Portugal de instrumentos de avaliação da criatividade validados para populações adultas e tendo em conta o crescente interesse das organizações na avaliação desta dimensão, julgámos de todo o interesse efectuar um estudo preliminar, para analisar as características psicométricas do TCT-DP numa amostra de adultos trabalhadores portugueses.

Este será certamente um primeiro impulso que abrirá caminho a estudos mais aprofundados sobre a pertinência das diversas medidas de avaliação da criatividade para a população portuguesa.

\section{Método}

\section{Participantes}

A amostra deste estudo é uma amostra de conveniência constituída por 169 participantes, 69 masculinos, correspondendo a 40,83\% da amostra e 100 femininos, correspondendo a $59,17 \%$, de idades compreendidas entre os 18 anos e os 66 anos, trabalhadores com diferentes actividades profissionais (ex. Professores, Engenheiros, Operadores de Lojas, Auxiliares de Apoio Educativo, Investigadores) e habilitações literárias diversas (do $4^{\circ}$ ano de escolaridade até ao Doutoramento).

\section{Instrumento}

O instrumento usado neste trabalho, como foi referido anteriormente, é o TCT-DP (Test for Creative Thinking - Drawing Production), apresentado mais recentemente por Urban e Jellen (1996). 
A operacionalização da variável no TCT-DP é realizada através da produção de desenhos, incompletos, de maneira a conseguir o máximo de flexibilidade como expoente da criatividade, ao invés de utilizar figuras ou símbolos relacionados com conceitos, possibilitando, assim, que as figuras incompletas possuam apenas significados vagos e convencionais. O desenho é avaliado por um conjunto de critérios que representam o construto teórico. As figuras, entre si, possuem uma grande sugestibilidade para respostas estereotipadas para que os participantes com maiores graus de criatividade criem possibilidades diferentes de respostas, levando a uma maior selectividade e validade do teste. A folha de teste (quer a Forma A, quer a Forma B) é constituída por seis fragmentos: um semicírculo, um ponto, um grande ângulo recto, uma linha curva, uma linha descontínua e um pequeno quadrado aberto, fora do quadrado grande de resposta. Estes seis fragmentos do instrumento foram construídos de acordo com os seguintes pontos: geométricos e não-geométricos, redondos e planos, singulares e composicionais, inteiros ou partidos, dentro e fora da figura dada, colocados irregularmente no espaço dado e incompletos. Existe também um outro elemento importante, o quadrado grande, que juntamente com o quadrado pequeno serve o propósito de analisar a informação relacionada com a decisão de risco e a quebra de fronteiras ou limites.

A análise das respostas que podem ser construídas com estes fragmentos, levaram à criação de 14 critérios chave que juntos, constituem o construto do TCT-DP, e que servem como critérios de avaliação, descritos de seguida:

I. Continuações (Cn): qualquer uso, continuação ou extensão dos fragmentos dados.

II. Completações (Cm): qualquer adição, complemento, completamento, ampliação ou suplemento feito à figura usada, dada ou continuada.

III. Novos Elementos (Ne): qualquer figura, símbolo ou elemento novo.

IV. Conexões efectuadas com uma linha (Cl): entre dois fragmentos e/ou novos elementos.

V. Conexões efectuadas que contribuem para um tema (Cth): qualquer figura que contribua para um tema composto ou global.

VI. Quebra do limite dependente do fragmento (Bfd): qualquer uso, continuação ou extensão do pequeno quadrado localizado fora do quadrado grande.

VII. Quebra do limite independente do fragmento (Bfi): qualquer quebra ou continuação da figura que passe os limites do quadrado grande.

VIII. Perspectiva (Pe): Qualquer tentativa para passar de duas a três dimensões. 
IX. Humor e afectividade (Hu): qualquer desenho que se relacione com uma resposta humorada, que mostre afecto, emoção ou um forte poder expressivo.

X. Não convencional, a (Uc, a): qualquer manipulação do material.

XI. Não convencional, b (Uc, b): qualquer elemento surrealista, ficcional ou abstracto no desenho.

XII. Não convencional, c (Uc, c): qualquer uso de símbolos ou sinais.

XIII. Não convencional, d (Uc, d): uso não convencional de fragmentos dados.

XIV. Velocidade (Sp): relacionado com o tempo gasto na produção do desenho.

As investigações mostraram que os sujeitos reagem de maneira diferente às figuras dadas, pois uns vêem imediatamente o desenho a fazer, outros começam passo por passo e outros têm dificuldade em sair da forma estereotipada do desenho e, por isso, foi decidido entregar uma segunda folha de teste (Forma B), similar, para efectuar maior justiça às capacidades individuais de cada um. Esta usa o desenho original mas com uma rotação de $180^{\circ}$.

A cada um dos 14 critérios é atribuída determinada pontuação (que pode variar entre os zero e os seis pontos), e é a soma delas que representa a classificação final do teste. Os autores indicam que pequenas variações na cotação não produzem grandes diferenças na classificação final, pois a pontuação total é relevante e o teste pretende ser apenas um instrumento que analise e aceda às aptidões criativas de uma maneira global.

As normas estandardizadas para o TCT-DP foram construídas a partir do resultado de vários pequenos estudos. O primeiro estudo foi conduzido de 1988 até 1993 e envolveu 2519 estudantes alemães (Urban, 2004; 2005). Os resultados mostraram uma correlação fraca positiva entre a média de habilitações escolares e a pontuação no TCT-DP. Não foram encontradas diferenças estatisticamente significativas entre os estudantes masculinos e femininos e, no que diz respeito à variável idade, a partir dos 11 anos, não foram encontradas diferenças estatisticamente significativas na população escolar.

Após vários estudos e um feedback de vários investigadores internacionais, as normas derivadas da amostra da população alemã, deverão ser aplicáveis a outras populações e outros países, principalmente aqueles que possuem uma cultura Europeia ou ocidental e/ou terreno socio-económico similar. A distribuição da pontuação é feita em sete grupos: A- Muito inferior à média; B- Inferior à média; C- Na média; D- Superior à média; E- Muito Superior à média; F- Extremamente Superior à média; e G- Fenomenal. 
As classificações são calculadas de igual modo para as Formas A e B, assim como para resultados combinados $(A+B)$, devendo sempre considerar-se as três pontuações aquando das interpretações. As normas possuem classificações de acordo com a idade e habilitações literárias.

A fidelidade do instrumento foi também analisada. Nos vários estudos realizados, a fidelidade de pontuação e a fidelidade inter - itens obtiveram uma correlação elevada. O teste mostrou uma elevada diferença de fidelidade entre os $25 \%$ maiores e menores desempenhos no teste.

Os autores reportam um coeficiente de Pearson de .95 para avaliadores treinados. O teste-reteste possui um valor de .46.

$\mathrm{Na}$ análise factorial de componentes efectuada para as Formas $\mathrm{A}$ e B, foram encontrados seis factores distintos: I- Utilização de fragmentos directos; II- Composição e ligações efectuadas por linhas ou que contêm um tema; III- Perspectiva e Velocidade; IV- Não Convencional e Humor na Forma A; V- Não Convencional e Humor na forma B; e por fim VI- Novos elementos, dentro e fora do espaço de desenho.

Quanto à validade do teste, visto não existirem instrumentos directamente comparáveis com o TCT-DP, é - nos difícil apresentar uma resposta simples. Contudo, toda a informação reunida sobre outros instrumentos deve ser considerada, como por exemplo aqueles que avaliam o quociente intelectual. Espera-se uma baixa correlação, ou apenas aparentemente positiva, entre o TCT-DP e os tradicionais testes de O.I.. Os estudos de Wolanska e Neçka (cit. por Urban, 2004), referidos anteriormente, contribuíram para esta verificação.

\section{Procedimento}

O teste aplicado num lugar relaxado e numa atmosfera confortável. A pressão do tempo, a tensão e o perigo de distracção e foram eliminados tanto quanto possível. Para um único examinador, o grupo sujeito à aplicação dos testes, não excedeu os 10-15 participantes e todos devem ter espaço suficiente para desenhar. Foram fornecidas as duas formas do teste (A e B), uma após a outra. Cada participante trabalhou sozinho no seu teste, o que implica que todos mantivessem alguma distância entre si.

Todos os sujeitos receberam uma cópia do TCT-DP (forma A), com a página do desenho para cima, um marcador, um lápis ou marcador grosso. Ainda se pediu a todos os examinandos que escrevessem o seu primeiro nome, idade, sexo e habilitações literárias no topo. 
Quando todos estavam prontos para começar o teste, deram-se as seguintes instruções: "À vossa frente está um desenho incompleto. O artista que o começou foi interrompido antes de ele/ela saber o que iria sair dele. É-vos pedido que continuem este desenho incompleto. É permitido desenharem o que quiserem, tudo aquilo que colocarem no papel estará correcto. Quando acabarem, por favor façam-me sinal, para que o possa recolher (e entregar a Forma B)". O examinador contabilizou-se o tempo dispendido por execução. Quanto a este factor, e para evitar fazer referência ao tempo disponível, o examinador apenas indicou: "Apenas comecem a efectuar o vosso desenho e não se preocupem com o tempo. Mas não temos uma hora inteira para o completar."

Se o desenho foi concluído em menos de 12 minutos, o examinador contabilizou o tempo, apontando-o no canto superior direito e imediatamente entregou a forma B. Após os 15 minutos, todos os que estivessem a trabalhar na forma A deveriam acabar o seu trabalho. De seguida entregou-se a forma B.

Questões efectuadas pelos examinandos foram respondidas da seguinte maneira: "é-vos permitido desenhar o que quiserem, tudo está correcto, não existe hipótese de efectuarem erros."

Quando os examinandos concluíam os seus testes, era-lhes dito: "Se sabem algum nome ou título ou tema para o vosso trabalho, por favor, escrevam-no por cima do vosso desenho." O título foi pedido de início para a forma A e no final para a forma $B$.

Para a avaliação final do teste foi necessário algum treino. Por isso, as instruções de cotação detalhadas foram estudadas com muito cuidado e comparadas entre vários exemplos de desenho.

\section{Resultados}

Foi elaborada uma análise de diferença entre médias, no que diz respeito ao Sexo, Idade e Habilitações Escolares. O teste para amostras independentes foi utilizado em relação ao Sexo e foi utilizada a ANOVA, em relação às Habilitações Escolares e Idade. Foi também realizada a estatística descritiva para as pontuações nas duas formas.

De seguida, foi elaborada uma análise factorial de componentes principais com rotação Varimax e o cálculo de consistência interna do instrumento. Por fim, foi efectuada uma correlação entre as médias das pontuações das formas A e B e o cálculo dos percentis das mesmas para a amostra em estudo. 
A análise da diferença entre médias em relação ao sexo apontou diferenças significativas entre homens e mulheres, quer na forma A, quer na Forma B, evidenciando os homens níveis mais elevados de criatividade.

Tabela 1. Diferença entre Médias na Pontuação das Formas A e B do TCT-DP segundo o sexo

\begin{tabular}{lcccc}
\hline & Sexo & Média & Sig. & t \\
\hline \multirow{2}{*}{ Total da pontuação para a Forma A } & Masc. & 22.13 & $.005^{*}$ & \multirow{2}{*}{2.818} \\
& Fem. & 17,19 & $.005^{*}$ & \\
\hline \multirow{2}{*}{ Total da pontuação para a Forma B } & Masc. & 21.94 & $.03^{*}$ & \multirow{2}{*}{2.144} \\
& Fem. & 18.11 & $.03^{*}$ & \\
\hline
\end{tabular}

"pffi.05

Quanto à diferença de médias em função da Idade, foram encontradas diferenças estatísticamente significativas nos grupos etários constituídos, tanto na forma A como na forma B, a favor do grupo dos 18 aos 34 anos (grupo mais jovem). De facto este grupo apresentou diferenças significativas relativamente ao grupo mais velho (55-66anos), na Forma A, e apresentou diferenças estatísticamente significativas relativamente a qualquer um dos outros grupos etários (35-54 e 55-66 anos) na Forma B.

Tabela 2. Diferenças entre médias das pontuações das Formas A e B do TCT-DP segundo a idade.

\begin{tabular}{|c|c|c|c|c|c|c|c|}
\hline & Idades & Média & Sig. & Idades & $\begin{array}{l}\text { Diferença } \\
\text { entre } \\
\text { médias }\end{array}$ & Sig. & $\mathrm{F}$ \\
\hline $\begin{array}{l}\text { Total da pontuação } \\
\text { para a Forma A }\end{array}$ & $\begin{array}{l}\text { 18-34 Anos } \\
\text { 35-54 Anos } \\
\text { 55-66 Anos }\end{array}$ & $\begin{array}{l}21.30 \\
17.03 \\
11.89 \\
\end{array}$ & $.009^{*}$ & $\begin{array}{l}\text { 18-34 vs } \\
\text { 55-66Anos }\end{array}$ & 9.410 & $.003^{*}$ & 4.818 \\
\hline $\begin{array}{l}\text { Total da pontuação } \\
\text { para a Forma B }\end{array}$ & $\begin{array}{l}\text { 18-34 Anos } \\
\text { 35-54 Anos } \\
\text { 55-66 Anos }\end{array}$ & $\begin{array}{l}22.20 \\
17.03 \\
11.00\end{array}$ & $.001^{*}$ & $\begin{array}{c}18-34 \text { vs } \\
35-54 \text { anos } \\
18-34 \text { vs } \\
55-66 \\
\text { anos }\end{array}$ & $\begin{array}{r}5.164 \\
11.196\end{array}$ & $\begin{array}{l}.014^{*} \\
.000^{*}\end{array}$ & 6.971 \\
\hline
\end{tabular}

"pffi.o5

No que diz respeito à diferença entre médias em relação às Habilitações Escolares, não foram encontradas diferenças estatísticamente significativas nos grupos constituídos na forma A. No entanto, na forma B, as diferenças foram significativas a favor do grupos com maiores níveis de Habilitações Literárias (do $10^{\circ}$ ao $12^{\circ}$ ano e do Superior ao $12^{\circ} \mathrm{ano}$ ), ou seja, foram encontradas diferenças estatísticamente significativas entre o grupo do $1^{\circ}$ ao $9^{\circ}$ ano e o grupo do $10^{\circ}$ ao $12^{\circ}$ ano bem como entre o grupo do $1^{\circ}$ ao $9^{\circ}$ ano e o grupo Superior ao $12^{\circ}$ ano. 
Tabela 3: Diferenças entre médias das pontuações das Formas A e B do TCT-DP segundo as Habilitações Literárias

\begin{tabular}{|c|c|c|c|c|c|c|c|}
\hline & $\begin{array}{l}\text { Habilitações } \\
\text { Literárias }\end{array}$ & Média & Sig. & $\begin{array}{l}\text { Habilitações } \\
\text { Literárias }\end{array}$ & $\begin{array}{l}\text { Diferença } \\
\text { entre } \\
\text { médias }\end{array}$ & Sig. & $\mathrm{F}$ \\
\hline $\begin{array}{l}\text { Total da pon- } \\
\text { tuação para a } \\
\text { Forma A }\end{array}$ & $\begin{array}{c}1^{\circ} \text { ao } 9^{\circ} \text { ano } \\
10^{\circ} \text { ao } 12^{\circ} \text { ano } \\
>12^{\circ} \text { ano }\end{array}$ & $\begin{array}{l}16.81 \\
20.91 \\
19.73\end{array}$ & .199 & & & & 1.163 \\
\hline $\begin{array}{l}\text { Total da pon- } \\
\text { tuação para a } \\
\text { Forma B }\end{array}$ & $\begin{array}{c}1^{\circ} \text { ao } 9^{\circ} \text { ano } \\
10^{\circ} \text { ao } 12^{\circ} \text { ano } \\
>12^{\circ} \text { ano }\end{array}$ & $\begin{array}{l}15.69 \\
21.23 \\
21.27\end{array}$ & $.017^{*}$ & $\begin{array}{l}1^{\circ}-9^{\circ} \mathrm{Vs} 10-12^{\circ} \\
1^{\circ}-9^{\circ} \mathrm{Vs}>12^{\circ}\end{array}$ & $\begin{array}{l}-5.540 \\
-5.585 \\
\end{array}$ & $\begin{array}{l}.041^{*} \\
.009^{*}\end{array}$ & 4.150 \\
\hline
\end{tabular}

"pffi.05

A média das pontuações na forma A foi de 19.21, com um desvio padrão de 11.43, e na forma B de 19.67, com um desvio padrão de 11.54 .

Tabela 4: Estatística Descritiva para a Forma A e B

\begin{tabular}{lccccc}
\hline & $N$ & $M$ & D.P. & MD & MED \\
\hline Pontuação Forma A & 169 & 19.21 & 11.43 & 9 & 16.00 \\
\hline Pontuação Forma B & 169 & 19.67 & 11.54 & 12 & 16.00 \\
\hline
\end{tabular}

Nota. $M=$ Média; D.P.= Desvio Padrão; $M D=$ Moda; $M E D=$ Mediana

A correlação efectuada entre as formas A e B, apresentou um valor de .78, indicado uma forte correlação positiva entre as mesmas.

Foi realizada uma análise factorial de componentes principais com rotação Varimax, para as formas A e B, onde o KMO possui o valor de .770 para a forma A e .766 para a forma B. O índice de esfericidade do teste de Bartlett é de .ooo (formas A e B), indicando que os dados se adequam ao processo estatístico realizado. Os componentes foram agrupados em 5 factores na forma A, que explicam 68,63\% da variância total e em 4 factores para a forma $B$, que explicam 60,99\% do total da variância. Na forma $A$, no primeiro factor foram encontrados cinco critérios: Conexões Efectuadas com Linhas, Novos Elementos, Conexões que contribuem para um Tema, Perspectiva e Não convencional b; no segundo factor foram encontrados quatro critérios: Quebra do limite dependente do fragmento, Continuações, Quebra do limite independente do fragmento e Velocidade; no terceiro factor foram encontrados dois critérios: Completações e não Convencional d; ao quarto factor, com dois critérios pertencem: a Afectividade/Humor/Expressão Emocional e Não convencional c; por último, no quinto factor, foi encontrado somente um critério: Não convencional a. 
Tabela 5: Matriz Rodada na Forma A do TCT-DP

\begin{tabular}{|c|c|c|c|c|c|}
\hline & \multicolumn{5}{|c|}{ Componentes } \\
\hline & 1 & 2 & 3 & 4 & 5 \\
\hline $\mathrm{Cl}$ & .85 & & & & \\
\hline $\mathrm{Ne}$ & .80 & & & & \\
\hline Cth & .76 & & & & \\
\hline $\mathrm{Pe}$ & .64 & & & & \\
\hline Uc B & .41 & & & & \\
\hline $\mathrm{Bfd}$ & & .89 & & & \\
\hline $\mathrm{Cn}$ & & .76 & & & \\
\hline $\mathrm{Bfi}$ & & .75 & & & \\
\hline Sp & & .55 & & & \\
\hline $\mathrm{Cm}$ & & & .80 & & \\
\hline UcD & & & .78 & & \\
\hline Uc C & & & & .85 & \\
\hline $\mathrm{Hu}$ & & & & .71 & \\
\hline UcA & & & & & .92 \\
\hline
\end{tabular}

O primeiro factor na forma B, é constituído por três critérios: Quebra do limite dependente do Fragmento, Continuações e Quebra do limite independente do Fragmento; o segundo factor é constituído por cinco critérios: Humor/afectividade/ Expressão Emocional, Velocidade, Perspectiva, Não convencional e Completações; no terceiro factor foram encontrados quatro critérios: Conexões efectuadas com linhas, Conexões que contribuem para um tema, Novos Elementos e Não Convencional b; por último, no quarto factor, foram encontrados dois critérios: Não convencional c e Não convencional a.

Tabela 6: Matriz Rodada na Forma B do TCT-DP

\begin{tabular}{|c|c|c|c|c|}
\hline & \multicolumn{4}{|c|}{ Componentes } \\
\hline & 1 & 2 & 3 & 4 \\
\hline Bfd & .83 & & & \\
\hline $\mathrm{Cn}$ & .72 & & & \\
\hline $\mathrm{Bfi}$ & .56 & & & \\
\hline $\mathrm{Hu}$ & & .39 & & \\
\hline Sp & & .36 & & \\
\hline $\mathrm{Pe}$ & & .75 & & \\
\hline UcD & & .72 & & \\
\hline $\mathrm{Cm}$ & & .70 & & \\
\hline $\mathrm{Cl}$ & & & .82 & \\
\hline Cth & & & .71 & \\
\hline $\mathrm{Ne}$ & & & .62 & \\
\hline Uc B & & & .58 & \\
\hline Uc C & & & & .76 \\
\hline UcA & & & & .51 \\
\hline
\end{tabular}


Quanto à análise da Consistência Interna, a forma A possui um Alpha de Cronbach de .82 e a forma $B$ de .80 , indicando que ambas possuem uma elevada consistência interna.

Tabela 7: Análise da Consistência interna na Forma A e B

\begin{tabular}{lcc}
\hline & Número de Itens & Alpha $(\alpha)$ de Cronbach \\
\hline Forma A & 14 & .82 \\
\hline Forma B & 14 & .80 \\
\hline
\end{tabular}

\section{Discussão}

A análise da criatividade tem avançado lentamente em Portugal, em parte devido à carência de instrumentos de avaliação validados para a população portuguesa. O objectivo desta investigação foi analisar um instrumento (TCT-DP) que avalia o pensamento criativo e efectuar um estudo preliminar das suas qualidades psicométricas, contribuindo assim para futuras investigações com o TCT-DP, de Urban e Jellen (1996).

Originalmente, Jellen e Urban (1986) não encontraram diferenças significativas nos níveis de criatividade em relação à variável Idade, e verificaram que a mesma não diferia a partir dos 11 anos de idade. Os resultados desde trabalho apontam na direcção oposta, indicando que existem diferenças significativas nos níveis de criatividade, apontando o grupo mais jovem (18-34 anos) como aquele que detém níveis mais elevados de criatividade. Em primeiro lugar, esta diferença em relação à variável Idade pode ser interpretada devido ao facto da amostra deste estudo ser de conveniência. Em segundo lugar, também poderemos colocar a hipótese dos sujeitos mais novos, incluídos no grupo etário mais jovem, poderem efectivamente evidenciar níveis de criatividade mais elevados, pois terão sido submetidos, ao longo da sua vida, a um menor número de crivos escolares e mesmo empresariais, tradicional e eventualmente penalizadores das atitudes mais criativas por parte dos sujeitos. Inversamente, poderemos conceber a hipótese dos sujeitos mais velhos, inseridos no grupo etário mais jovem considerado, poderem eles próprios ser mais criativos devido à sua maior experiência e exigência escolar e profissional. Paralelamente, poderíamos conceber a hipótese dos sujeitos dos grupos etários mais velhos não serem tão frequentemente chamados a serem criativos, nos seus contextos profissionais. Seria, portanto, interessante fazer um estudo semelhante mas mais alargado, por forma a permitir diferenciar níveis etários de forma mais fina e a considerar outras variáveis em simultâneo. No que diz respeito à variável Sexo, este estudo encontrou diferenças significativas, ao contrário dos estudos dos autores, mas somente na forma A. A forma B não apresentou diferenças significativas, indo de encontro aos resultados dos investigadores. No nosso caso, os 
homens apresentaram níveis mais elevados de criatividade, comparativamente às mulheres, na Forma A do TCT-DP. De salientar que, ao contrário da investigação dos autores do teste, esta amostra foi somente constituída por sujeitos adultos e activos nas mais diversas profissões, revelando, os homens, profissões mais técnicas e com um perfil mais artístico, o que poderia explicar os seus melhores resultados neste teste de criatividade que se baseia na produção de desenhos. No entanto, atentemos ao facto desta diferença apenas se registar a nível da Forma A e não a nível da Forma B do teste de criatividade. Na tentativa de explicar estes resultados discrepantes, poderemos levantar a hipótese de que pelo facto dos sujeitos terem sido submetidos a nova actividade (Forma B), em tudo semelhante à Forma $\mathrm{A}$, se tenham feito diluir eventuais diferenças entre homens e mulheres. Diferenças essas respeitantes às exigências nas suas actividades profissionais diárias, já que parece exigir-se mais criatividade aos homens, bem como eventualmente respeitantes à atitude de maior conformismo que mais frequentemente se espera das mulheres, nos seus contextos familiares e escolares.

Em relação às Habilitações Escolares, os autores do teste não encontram diferenças nos respectivos níveis de criatividade. No entanto, neste estudo, foi encontrada uma diferença estatisticamente significativa em relação às Habilitações Literárias, mas somente na forma B, evidenciando os sujeitos com maiores Habilitações Literárias, maiores níveis de criatividade. Mais uma vez, estes resultados podem ser interpretados ou devido às características da amostra de conveniência ou devido ao efeito de uma certa habituação e capacidade para se desprenderem dos seus níveis de conformismo iniciais.

Outra das diferenças principais entre os resultados do nosso estudo e os dos autores do teste, regista-se ao nível do agrupamento dos critérios em vários factores. Os autores originais agruparam os critérios em seis factores, sempre analisando as duas formas ( $\mathrm{A}$ e B). Assim, existiram diferenças no agrupamento dos critérios em factores em relação aos dados dos autores. Além desta diferença, os próprios factores são diferentes entre a forma $A$ e $B$, neste estudo preliminar. Estes resultados parecem sugerir um agrupamento diferente de critérios em relação aos dos autores, mas há que ter ainda algumas reservas devido à amostra de conveniência utilizada.

Apesar das diferenças encontradas neste trabalho, entre as formas A e B, no que diz respeito às diferenças de Sexo, Idade, Habilitações Escolares e agrupamento de factores, detectámos uma correlação positiva forte entre os totais das duas formas A e B. Esta correlação entre as duas formas já era por nós esperada se atendermos ao facto da forma B ser em tudo semelhante à forma $A$, apenas se diferenciando a partir da rotação de 180 graus que Ihe foi imprimida. Esta correlação está de acordo com os dados dos autores, sugerindo assim a utilização das 
duas formas para avaliar o pensamento criativo. Os autores utilizam a forma $A$ e sugerem a utilização da forma $B$, para que os sujeitos, após terem elaborado a forma A, se libertem dos estereótipos e utilizem melhor as suas capacidades criativas. Com o intuito de utilizar futuramente este instrumento como teste de selecção de sujeitos para determinados cargos, e visto não existir uma diferença significativa entre as pontuações da forma $A$ e B, uma das conclusões deste estudo é que se utilize somente a forma $A$, pois a mesma é suficiente para analisar o pensamento criativo dos indivíduos.

Em relação à Consistência interna do TCT-DP, a análise revelou valores de Alpha de Cronbach elevados, evidenciando uma boa consistência interna, tanto na forma A, como na forma B. Estes resultados vão ao encontro do estudo de Jellen e Urban (1986), assim como de Rudowicz e Hui (2004). Ao nível da análise das qualidades psicométricas, resta efectuar um estudo aos diferentes tipos de fidelidade do teste: inter-cotadores e teste-reteste, em Portugal. Muitos dos estudos feitos com o TCT-DP realizados internacionalmente já a comprovaram, mas seria sempre aconselhável uma análise a partir da população Portuguesa.

Este estudo preliminar faz parte de um estudo mais alargado de validação do TCT-DP à população portuguesa e levantou interessantes pistas de investigação para estudos futuros com amostras mais alargadas e diversificadas. Esperemos que se constitua aqui uma boa oportunidade para que mais investigadores se interessem pelas questões da criatividade, formas de a avaliar e pela caracterização dos mais diversos segmentos da nossa população.

\section{Referências bibliográficas}

Amabile, T. M. (1983). The social psychology of creativity. New York: Springer-Verlag.

Barron, F., \& Harrington, D. M. (1981). Creativity, intelligence and personality. Annual Review of Psychology, 32, 439-476.

Csikszentmihalyi, M. (1988a). Society, culture, and person: a systems view of creativity. In R. J. Sternberg (Ed.), The nature of creativity: contemporary psychological perspectives (pp. 325-339). NY: Cambridge University Press.

Csikszentmihalyi, M. (1988b). Where is the evolving milieu? A response to Gruber. Creativity Research Journal, 1, 60-62.

Gardner, H. (1988). Creative lives and creative works: A synthetic scientific approach. In R. J. Sternberg (Ed.), The nature of creativity: contemporary psychological perspectives (pp. 298-321). NY: Cambridge University Press.

Guilford, J.P. (1950). Creativity. American Psychologist, 5, 444-454.

Jellen, H.G., \& Bugingo, E. (1989). Assessing creative problem potencial in engineering students: the application of the Test for Creative Thinking-Drawing Production on pentathlon participants. Journal of Studies in Techical Careers, 11, 223-235. 
Jellen, H., \& Urban, K.K. (1986). The TCT-DP (Test for Creative Thinking - Drawing Production): An instrument that can be applied to most age and ability groups. Creative Child and Adult Quarterly, 11, 138-155.

Rudowicz, \& Hui (2004). Applicability of the Test of Creative Thinking - Drawing Production for assessing creative potentials of Hong Kong adolescents. Gifted Child Quarterly, 48, 202-218.

Simonton, D. K. (1988). Creativity, leadership, and chance. In R. J. Sternberg (Ed.), The nature of creativity: contemporary psychological perspectives (pp. 386-426). NY: Cambridge University Press.

Stein, M. I. (1987). Creativity research at the crossroads: A 1985 perspective. In S. G. Isaksen (Ed.), Frontiers of creativity research: Beyond the basics (pp. 417-427). New York: Plenum Press.

Sternberg. R.J., \& Lubart, T.I. (1991). An Investment Theory of creativity and its development. Human Development, 34, 7-15.

Sternberg. R.J., \& Lubart, T.I. (1996). Investing in creativity. American Psychologist, 51677 688.

Torrance, E. P. (1976). Criatividade: Medidas, testes e avaliações. São Paulo: IBRASA.

Torrance, E. P. (1988). The nature of creativity as manifest in its testing. In R. J. Sternberg (Ed.), The nature of creativity: contemporary psychological perspectives (pp. 43-75). NY: Cambridge University Press.

Treffinger, D. J. (1987). Research on creativity assessment. In S. G. Isaksen (Ed.), Frontiers of creativity research: Beyond the basics (pp. 204-215) New York: Plenum Press.

Urban, K. K. (1991). On the development of creativity in children. Creativity Research Journal, 4, 177-191.

Urban, K.K.(2004)._Assessing Creativity: the test for creative thinking - drawing production (TCT-DP) the concept, application, evaluation, and international studies. Psychology Science, 46, 387-398.

Urban, K. K.(2005). Assessing creativity: The Test for Creative Thinking - Drawing Production (TCT-DP). International Education Journal, 6, 272-280.

Urban, K.K, \& Jellen, H.G. (1986). Assessing creative potential via drawing production: The Test for Creative Thinking - Drawing Production (TCT-DP). In A.J. Cropley, K.K Urban, H. Wagner \&W. Wieczerkowski (Hrsg.), Giftedness: A continuing worldwide challenge (S.163-169). New York, NY: Trillium Press.

Urban, K.K., \& Jellen, H.G. (1996). Manual of Test for Creative Thinking- Drawing Production (TCT-DP). Amesterdão: Harcourt Test Publishers.

Walberg, H. J. (1988). Creativity and talent as learning. In R. J. Sternberg (Ed.), The nature of creativity: contemporary psychological perspectives (pp. 340- 361). New York: Cambridge University Press. 


\section{Preliminary study of the Test for Creative Thinking - Drawing Produc- tion (TCT-DP)}

We intent to do a preliminary study of the test TCT-DP - Test of Creative Thinking and Drawing Production of Urban e Jellen (1986), that aims an holistic evaluation of the divergent thinking. The test (Forms A and B) is based on some fragments of pictures which the subjects must complete freely. Our sample, collected among certain Lisbon Human Resourses Consultant Companies, involves 169 adult (over 18 years old) portuguese workers with diverse Literary and Professional competences. Beyond some aspects of the instrument adaptation to the portuguese population, some studies were made about que psychometric properties of the instrument with our sample. This study pointed out some clues for further studies, and sugests the enlargement of the sample as well their diversification.

KEY-WORDS: Test for Creative Thinking-Drawing Production (TCT-DP), Creativity, Divergent Thinking, Preliminary study.

\section{Étudie préliminaire du Test for Creative Thinking-Drawing Production (TCT-DP)}

On veut accomplir une étude préliminaire du test TCT-DP - Test of Creative Thinking and Drawing Production, des auteurs Urban et Jellen (1986), que vise une analyse holistique du raisonnement divergent. Le test (Formes $A$ et $B$ ) se fonde en quelques fragments de figures que les sujets doivent accomplir de la façon dont ils veut. L'échantillon d'on nous avons parti, obtenu a partir de quelques Entreprises de Récrutement de la région de Lisbonne, est composé par 169 employés portugais, avec plus de 18 ans et avec plusieurs habilitations litéraires et profissionels. Au-delà de l'adaptation de l'instrument à la population portugaise, on a realisé quelques études sur les qualités psichometriques du test pour la population considerée. Cette étude a signalée quelques pistes d'investigations futures, préssuposant une élargissement de l'étaillon et sa diversification.

MOTS-CLÉS: Test for Creative Thinking- Drawing Production (TCT-DP), Creativité, Raisonnement Divergent, Étude préliminaire. 